\title{
Size and Shape of the Lingual Surface of the Upper Molar
}

\author{
Akihiro NUMATA
}

(Received 28 April and accepted 4 July 1988)

Key words: lingual surface, upper molar, tooth size, cervical constriction

\begin{abstract}
The lingual surface of the upper first and second molars was metrically investigated. Four parameters were analyzed, i.e., the maximum and minimum lengths of the lingual surface in the mesiodistal direction, their ratio expressed as (min./max.) $\times 100$, and the angle formed by these two lengths, representing cervical constriction. The two lengths were larger in males than in females for both the first and second molars. The ratio was significantly larger for the first molar than for the second molar. It was consequently suggested that cervical constriction was stronger in the first molar than in the second molar. The angle did not show any significant differences either between the sexes or between the two kinds of molar.
\end{abstract}

\section{Introduction}

So far, dental morphological studies have centered on overall size such as mesiodistal diameter and buccolingual diameter. However, recent investigations have revealed that morphological features responsible for crown morphology, such as cusps and ridges, demonstrate different variability in comparison with overall $\operatorname{size}^{[1,2]}$.

Quantitative studies on the height and size of cusps and morphology of ridges have therefore concentrated mainly on the occlusal surface of molars ${ }^{[3,5]}$. Morphologically important features are found not only on the occlusal surface, but also on the other four sides, i.e., the lingual, buccal, mesial and distal proximal surfaces.

The changing morphology of the upper molars from an anterior to a posterior form is found not only on the occlusal surface but also on the buccal, lingual and proximal surfaces. This change shows several regular patterns ${ }^{[6,8]}$, one of which is constriction of the tooth neck seen on buccal and lingual surface, a feature that can be used for judgements on tooth type and reductive trends in molars ${ }^{[8,9]}$.

OZAKI et al. ${ }^{[10]}$ measured the maximum and minimum diameters of the buccal surface of upper molars. His results revealed a relationship between the most constricted part and the most swollen part, employing the ratio of the above two measurements. The present study examined the sequential change of this relation-

沼田昭浩: Department of Anatomy, Nihon University School of Dentistry at Matsudo, 2-870-1, Sakaecho Nishi, Matsudo, Chiba, Japan.

Originally submitted as a doctor's thesis. 
ship in the molar row.

The lingual surfaces of the maxillary first and second molars were measured in the present study on the basis of OzAKI's method ${ }^{[10]}$. The index representing the constriction of the tooth neck was calculated, and the results were compared with those of his report on the buccal surface.

\section{Materials and Methods}

Materials used were maxillary molars preserved in the Department of Anatomy, Nihon University School of Dentistry at Matsudo. The total sample size was 260, and consisted of first molars (male: 76, female: 54 ) and second molars (male: 61, female: 69). Two sets of lines were drawn manually with Indian ink on the border between the lingual surface and mesial proximal surface and between the lingual surface and distal proximal surface.

Each tooth was set on a free arm table and the tooth axis ${ }^{[11]}$ was positioned perpendicularly to the lens of a Polaroid MP-4 camera with a 50-mm lens, then the lingual surface was photographed.

The contour and the border lines in each photograph were traced onto a plastic tracing sheet (Orthotrace). Figure 1 shows the geometric scheme used for the measurements. The tooth axis was defined as the $\mathrm{Y}$ axis. Point $a$ was defined as the most mesial point on the mesial border line, and point $b$ was the most distal point on the distal border line. Points $c$ and $d$ were intersections of the border lines and the cervical line. Two-dimensional coordinate values of these four points

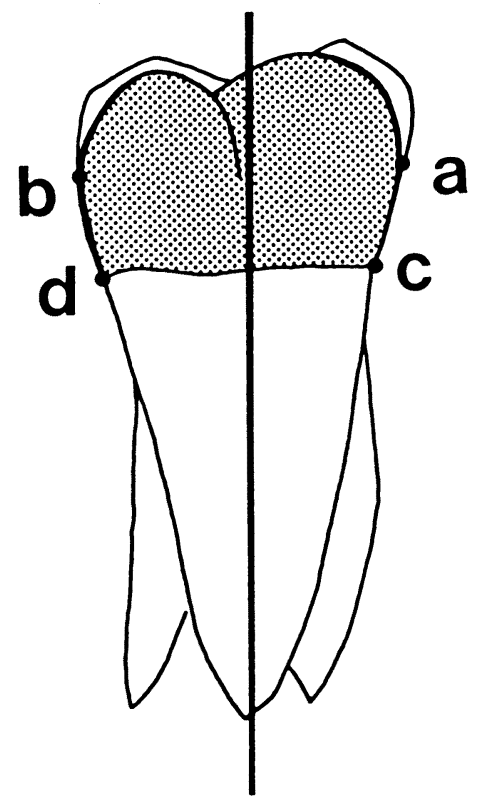

Fig. 1 Measuring points used in the present study.

The bold line in the center indicates dental axis.

Dotted pattern indicates lingual surface of the upper molar. 
were input with a digitizer (Gradimaster SS-4000). Then the perpendicular distances from these points to the $\mathrm{Y}$ axis were obtained.

The sum of the distances from $a$ and $b$ to the $\mathrm{Y}$ axis is defined as the mesiodistal distance (MD) of the lingual surface. Those of $c$ and $d$ to the $\mathrm{Y}$ axis were also combined to give the cervical mesiodistal diameter (CMD). The angle formed by two lines, one passing through points $a$ and $c$, and the other through $b$ and $d$, represents the cervical constriction on the lingual surface. This angle is called the lingual angle in the present study. The ratio $(\mathrm{MD} / \mathrm{CMD}) \times 100$ was also calculated as the MD diameter index. Mean values, standard deviation and coefficient of variation of these variables were obtained for each tooth and sex. Correlation coefficients were also analyzed for the first and second molars, separately. Statistical testing of differences in mean values between sexes and between teeth was carried out by Student's $t$ test.

\section{Results}

Table 1 shows the mean values and standard deviations of MD, CMD, the lingual angle and the diameter index for the first and the second molar. Mean values of MD and CMD were larger for first molars than for second molars in both males and females. No difference in the lingual angle was found between teeth. The index was larger for second molars than for first molars.

The significance of differences is shown in Table 2. MD, CMD and the index showed significant tooth difference, but the lingual angle did not show any difference in either males or females. A sex difference was found in MD and CMD for both first and second molars. However, the lingual angle and the index did not show any significant difference.

Table 1 Mean and SD of measurements for the lingual surface of upper molars

\begin{tabular}{|c|c|c|c|c|}
\hline Male & MD & CMD & Lingual Angle & Index \\
\hline $\begin{array}{c}6 \text { mean } \\
\text { S. D. }\end{array}$ & $\begin{array}{l}9.35 \\
0.49\end{array}$ & $\begin{array}{l}6.99 \\
0.49\end{array}$ & $\begin{array}{r}35.07 \\
4.30\end{array}$ & $\begin{array}{r}74.78 \\
3.96\end{array}$ \\
\hline $\begin{array}{c}7 \text { mean } \\
\text { S. D. }\end{array}$ & $\begin{array}{l}8.33 \\
0.57\end{array}$ & $\begin{array}{l}6.54 \\
0.43\end{array}$ & $\begin{array}{r}35.26 \\
6.17\end{array}$ & $\begin{array}{r}78.61 \\
4.38\end{array}$ \\
\hline Female & & & & \\
\hline $\begin{array}{l}6 \text { mean } \\
\text { S. D. }\end{array}$ & $\begin{array}{l}8.77 \\
0.53\end{array}$ & $\begin{array}{l}6.42 \\
0.54\end{array}$ & $\begin{array}{r}36.87 \\
7.17\end{array}$ & $\begin{array}{r}73.22 \\
4.87\end{array}$ \\
\hline $\begin{array}{l}7 \text { mean } \\
\text { S. D. }\end{array}$ & $\begin{array}{l}8.08 \\
0.56\end{array}$ & $\begin{array}{l}6.23 \\
0.45\end{array}$ & $\begin{array}{r}35.91 \\
5.29\end{array}$ & $\begin{array}{r}77.23 \\
4.54\end{array}$ \\
\hline
\end{tabular}


Table 2 Test of the significance of tooth size difference and sex difference

\begin{tabular}{|c|c|c|c|c|c|}
\hline & & MD & CMD & L. Angle & Index \\
\hline between teeth: & $\begin{array}{r}\mathrm{M} \\
\mathrm{F}\end{array}$ & $\begin{array}{l}6 \gg 7 \\
6 \gg 7\end{array}$ & $\begin{array}{l}6 \gg 7 \\
6>7\end{array}$ & $\begin{array}{l}6 \fallingdotseq 7 \\
6 \fallingdotseq 7\end{array}$ & $\begin{array}{l}6 \ll 7 \\
6 \ll 7\end{array}$ \\
\hline between sexes: & $\begin{array}{l}6 \\
7\end{array}$ & $\begin{array}{l}M \gg F \\
M \gg F\end{array}$ & $\begin{array}{l}M \gg F \\
M \gg F\end{array}$ & $\begin{array}{l}M \fallingdotseq F \\
M \fallingdotseq F\end{array}$ & $\begin{array}{l}M>F \\
M \fallingdotseq F\end{array}$ \\
\hline
\end{tabular}

6: first molar, 7: second molar, M: male, F: female

Significant levels are indicated as, $\gg: 1 \%,>: 5 \%$,

$\fallingdotseq$ : not significant.

Table 3 Correlation matrices of measurements for the lingual surface of upper molars

Male Female

\begin{tabular}{|c|c|c|c|c|c|c|c|}
\hline \multirow{3}{*}{6} & CMD & 0.76 & & & 0.62 & & \\
\hline & L. Angle & -0.12 & -0.51 & & -0.19 & -0.56 & \\
\hline & Index & 0.17 & 0.77 & -0.66 & -0.11 & 0.71 & -0.54 \\
\hline \multirow{4}{*}{7} & CMD & 0.66 & & & 0.65 & & \\
\hline & L. Angle & 0.23 & -0.37 & & 0.36 & -0.18 & \\
\hline & Index & -0.45 & 0.38 & -0.71 & -0.37 & 0.46 & -0.63 \\
\hline & & MD & CMD & L. Angle & MD & CMD & L. Angle \\
\hline
\end{tabular}

Table 3 shows the correlation coefficients of the four parameters in males and females, respectively. The correlation between MD and CMD was high and positive in both the first and second molars, but that between the angle and the index was negative. The correlation between the index and CMD was positive, but its coefficient was higher in the first molar than in the second molar in both sexes.

\section{Discussion}

Constriction of the cervical part of a molar is an important morphological feature not only from an anatomical viewpoint, but also in clinical dentistry. OZAKI, et al. ${ }^{[10]}$ measured the maximum and minimum diameters of the buccal surface of the upper molar. The relative size of the maximum diameter to the minimum one represents the ratio of constriction. They reported that the constriction is stronger in the first molar than in the second molar.

FUJITA $^{[8]}$ described that the buccal view of the upper first molar gave strong constriction at the cervical part of the crown and the mesiobuccal cusp projecting toward the mesial proximal surface. With these morphological features, the angle is formed at the cervical part by the contours of the crown and root of the first molar. However, the second and third molars do not show this angle. Ozaki's 
results are thought to provide metric evidence for this observation.

The lingual surface of the upper molar was also described by FUJITA ${ }^{[8]}$ as having a shape similar to that of the buccal surface, but being smaller in size and more rounded than the buccal surface. No metric study of the background to this observation has yet been done.

The maximum diameter of the lingual surface was significantly greater in the first molar than in the second molar in both males and females. The mesiodistal diameter of the crown also showed the same tendency ${ }^{[7,12,13]}$. The minimum diameter in females, however, was not different between the first and second molars. This suggests that variability in different parts of the tooth is not equal to that of mesiodistal diameter. This dimension is traditionally important, but it would mask other smaller morphological features which could be genetically important morphological traits.

The cusps composing the lingual surface are the protocone and hypocone. There is no difference in the distance between the tips of these cusps in Japanese $^{[14]}$ and also in Australian Aboriginals ${ }^{[15,16]}$. TownSEND ${ }^{[17]}$ measured the buccolingual diameter and intercuspal distance of the upper premolars, and found that the sex difference was significant in the buccolingual diameter, but not significant in the intercuspal distance. The cuspal tip is the portion at which initial calcification begins. He concluded that the location of this initial calcification is similar in both sexes, but that the volume or deposition rate of enamel is higher in males. The sex difference in the mesiodistal distance for the lingual surface seen in the present study is probably related to the overall size of the crown, particularly the most swollen part and cervical portion in which enamel deposition starts and ends later than at the cuspal tips.

SAKURAI ${ }^{[18]}$ investigated two kinds of occlusal surface areas of the upper first molar. One was the area encircled by the outer limit of the occlusal profile and the other was the occlusal table enclosed by the four cuspal tips and the marginal ridges between them. A sex difference was found in the latter, but not in the former. This finding would appear to be related to TowNSEND's ${ }^{[17]}$ and our results.

The lingual angle and the diameter index represent constriction at the cervical portion. Mean values of the index in males and females differ between the first and second molars, but those of the angle are fundamentally the same. A difference in the index indicates that the distance between the maximum and the minimum diameter is greater in the first molar than in the second molar. This finding is different from that of OzAKI's ${ }^{[10]}$ regarding the buccal surface. In Fujita's macroscopic descriptions, he previously mentioned the needs for modification from the viewpoint of cervical constriction.

The morphological significance of the difference in the constriction between the buccal and lingual surface is still not clear. However, it is probably related to the relative positions of the paracone and metacone. The maximum diameter of the buccal surface depends on the development of these two cusps. In maxillary dentition, the size of the buccal cusps could be morphologically influenced by the distal marginal protrusion, because the contact point comes closer to the buccal side. The mesial surface of the first molar seems to project mesially because of its 
contact with the second premolar.

On the lingual surface, on the other hand, the influence of marginal portion or contact with the premolar is negligible, and the development of the hypocone and protocone would exert a morphological influence. Spee's curve and prosthodontic contour ${ }^{[19,20]}$ would also cause a difference between molar buccal and lingual surfaces.

ROSENSTIEL ${ }^{[20]}$ made mesiodistal sections of the molars and investigated the angle between the contours of the crown and root at the cervical part of the proximal surface. According to his report, this angle is not different between the first molar and the second molar. The measurement adopted by him was near the center of the crown, unlike the case in OzAKI's ${ }^{[10]}$ and the present study. The different results in these studies might have been due to the location of the measurement. The morphology of the buccal surface and lingual surface measured in both Ozaki's and the present study may be strongly influenced by traits which are appropriate for this surface, such as the development of the hypocone and the existence of Carabelli's cusp.

The correlation coefficients between the maximum diameter and the minimum diameter were positive and relatively high in both the first and second molars. This suggests that the shapes of these two surfaces are similar. Correlation coefficients between the index and the minimum diameter were higher in the first molar than in the second molar, and the index was thought to depend on the size of the minimum diameter. It was also suggested that the variance of the minimum diameter was greater than that of the maximum diameter. These facts are understandable when the coefficient of variation in the maximum diameter in the first molar (males: 5.21, females: 6.04) is compared with that in the minimum diameter (males: 8.07, females: 8.47).

So far, morphological studies of the molar have focused on the occlusal surface, and little attention has been paid to the buccal or lingual surface. However, the results of this study suggest the possibility that the measurement of these surfaces would provide important morphological information in the fields of physical anthropology and dental anatomy.

\section{References}

[1] BiggerstafF, R.H.: The basal area of posterior tooth crown components: the assessment of within-tooth variation of premolars and molars, Am. J. Phys. Anthropol., 31, 163-170, 1969

[2] G ARN , S.M.: Genetics of dental development. In The Biology of Occlusal Development, J. A. McNamara, ed., Ann Arbor, Michigan: Craniofacial Growth Series, 1977

[3] Ozaki, T., Kanazawa, E., Sekikawa, M. and Sakurai, S.: Three-dimensional measurements of occlusal surface of lower first molars in a Dutch population, Jpn. J. Oral Biol., 26, 241-248, 1984

[4] Kanazawa, E., Sekikawa, M. and Ozaki, T.: Three-dimensional measurements of the occlusal surface of upper molars in a Dutch population, J. Dent. Res., 63, 1298-1301, 1984

[5] Sekikawa, M., Kanazawa, E. and Ozaki, T.: Study of the cuspal ridges of the upper first molars in a modern Japanese population, Acta anat., 129, 159-164, 1987

[6] OzaKI, T., OhNuKI, E. and Tsuruoka, M.: Occlusal surface index of the molars in Indians, J. Anthrop. Soc. Nippon, 85, 237-243, 1977

[7] OZAKI, T.: The reduction index of Japanese teeth, Acta Anat. Nippon., 35, 563-577, 1960 (in 
Japanese)

[8] Fujita, T.: Ha no Kaibougaku (Dental Anatomy), 21st ed., p. 70-74, Kanehara Shuppan, Tokyo, 1977 (in Japanese)

[9] Fujita, T., Hoshi, H., Isokawa, S., Kimura, K., Ozaki, T., Saheki, M. and Sakura, H.: The possibility of identification on the human isolated teeth, J. Anthrop. Soc. Nippon, 68, 43-56, 1960 (in Japanese)

[10] Ozaki, T., Kubota, K., Sekikawa, M. and Kawasaki, T.: Mesiodistal crown diameter index of the buccal surface of upper molars in the Japanese, J. Nihon Univ. Sch. Dent., 22, 45-54, 1980

[11] Fujita, T.: Ha no Keisoku Kijun ni Tsuite (On the standard measurement of the teeth), J. Anthrop. Soc. Nippon. 61, 1-6, 1949 (in Japanese)

[12] Hanihara, H.: Statistical and comparative studies of the Australian Aboriginal dentition, Bull. Univ. Mus. Univ. Tokyo, No. 11, 6-36, 1976

[13] Sexikawa, M.: Fourier analysis of the dental arch form, Jpn. J. Oral Biol., 28, 43-61, 1983 (in Japanese)

[14] Kanazawa, E., Sekikawa, M. and Ozaki, T.: Three-dimensional measurement of the occlusal surface of upper first molars in a modern Japanese population, Acta anat., 116, 90-96, 1983

[15] Ozaki, T., Kanazawa, E., Sekikawa, M. and AKaI, J.: Three-dimensional measurements of the occlusal surfaces of the upper molars in Australian Aboriginals, Aust. Dent. J., 32, 263-269, 1987

[16] Sekikawa, M., Kanazawa, E. and Ozaki, T.: Three-dimensional measurements of the occlusal surfaces of lower first molars of Australian Aboriginals, Am. J. Phys. Anthropol., 71, 25-32, 1986

[17] Townsend, G.C.: Intercuspal distances of maxillary premolar teeth in Australian Aboriginals, J. Dent. Res., 64, 443-446, 1985

[18] Sakurai, S.: Study on the occlusal surface area of the upper first molar in Japanese dentitions, Nihon Univ. J. oral Sci., 12, 326-332, 1986 (in Japanese)

[19] SAIto, H.: Studies on the side view of the mandibular posterior tooth crown, Aichi-Gakuin J. Dent. Sci., 14, 705-715, 1964 (in Japanese)

[20] Rosenstiel, E.: Contour measurement of posterior teeth, J. Pros. Dent., 14, 705-715, 1964 